\title{
VIOLENCIA DOMÉSTICA Y NUEVOS MODELOS DE MUJER: Te doy mis ojos o la importancia de la mirada femenina
}

\author{
Ana Isabel Blanco García \\ Universidad de León
}

Es divertido: todos los hombres que me encuentro quieren

protegerme. No puedo imaginarme de quién.

Mae West

No nos une el amor;

Sino el espanto.

Será por eso qeçue te quiero tanto.

Jorge Luis Borges

\section{Resumen}

En este trabajo nos proponemos explorar, a través del cine, (en concreto tomando como base de la argumentación la película de Icíar Bollaín Te doy mis ojos) cómo se están perfilando en los últimos años unos nuevos modelos de ser mujer, que parece que incorporan las demandas del feminismo y en el que están implicadas cuestiones cruciales en torno a la identidad de las mujeres.

La llamada violencia doméstica, cuestión que trata de comprenderse en la citada película, es un grave problema social, razón por la cual debería ser, en la medida de lo posible, erradicado; pero también es un problema sociológico que necesita por ello ser explicado en términos científicos, lo que en buena medida nos ayudará al primer propósito, ligando con ello la teoría y la práctica. 


\section{Introducción}

A pesar de que durante el siglo XX han tenido lugar importantes transformaciones dirigidas a conseguir una situación de mayor igualdad entre los sexos, lo cierto es que en nuestras sociedades postindustriales las mujeres siguen manteniéndose en un segundo plano, o lo que es lo mismo, no se ha producido la eliminación del patriarcado como organización social en la que los puestos clave de poder (político, religioso, económico y militar) están mayoritariamente en manos de los varones. La división del trabajo que resulta del mismo está cada vez más cuestionada, pero no por ello podemos decir que haya desaparecido.

En consonancia con esto, se sigue manteniendo la contraposición entre lo público y lo privado, entre lo productivo y lo reproductivo, reservándose este último como terreno casi exclusivo para las mujeres, quienes, aún accediendo a parte de las actividades de lo público, continúan siendo las responsables prácticamente en exclusividad del mismo. Hablamos de responsabilidad y no de poder, y esto es un punto importante. Las mujeres son responsables de lo que ocurre en el ámbito doméstico, pero bajo la atenta mirada del control social patriarcal, frente al que tienen que responder. Ellas deben comportarse de acuerdo con los modelos que el sistema patriarcal establece y si no lo hacen así, a menudo son castigadas, normalmente a través del control social informal (por ejemplo mediante expresiones como "es un ama de casa desastrosa", "no es una buena madre", "no es una buena esposa", "no organiza bien la economía familiar", "no es complaciente", "es gruñona”, etc.). E1 castigo extremo se expresa mediante las actitudes más violentas, lo que se ha venido a denominar en los últimos años violencia doméstica, que no es otra cosa que el ejercicio desnudo del poder de un representante de ese sistema patriarcal contra las mujeres con las que comparte ese ámbito doméstico.

Se trata como decimos de ejercicio del poder, que en los últimos tiempos se ha despojado de la autoridad que en otro momento tenía. El hombre 
que golpeaba a su esposa en épocas anteriores por no cumplir con las tareas de reproducción física y mantenimiento afectivo que, según un supuesto pacto social, le correspondían, no era víctima de la reprobación social, pues se consideraba que velaba por el mantenimiento del orden social establecido según esos modelos patriarcales, por lo que además de ejercer el poder estaba investido de autoridad (el reconocimiento legítimo de esa capacidad de obligar a otra persona a comportarse como uno quiera, a pesar de la resistencia).

En nuestra sociedad actual, nos encontramos en proceso de despojar de autoridad a esos comportamientos pero no hemos podido erradicarlos, como lo demuestran las cifras de mujeres muertas a manos de sus compañeros actuales o pasados (271 mujeres asesinadas por sus compañeros en los últimos 3 años en España). La persistencia de este tipo de comportamientos nos remite a la pervivencia de modelos patriarcales trasnochados al menos en algunos sectores de la población sobre todo masculina.

Las mujeres aceptamos mejor un cambio de las prescripciones de rol según el sexo, porque suponen la salida hacia lugares deseables, pero entre la población masculina hay sectores todavía muy reticentes. Como señalan Bonino (1998) y Ortega (1998) existe todavía un grupo considerable de varones, en un extremo mayores de 55 años y en el otro menores de 20 , que presentan actitudes sexistas propias de otros tiempos. Otros, aunque se manifiesten a nivel actitudinal a favor de la igualdad, no lo demuestran en su comportamiento efectivo. Este grupo estaría formado mayoritariamente por aquellos que tienen estudios superiores, solteros sin hijos, relacionados con mujeres que trabajan fuera y los habitantes de las grandes ciudades. Pero dentro de estos grupos existen diferentes concepciones, como los llamados de tipo utilitario, que se benefician de las aportaciones de las mujeres sin dar nada a cambio y los igualitarios unidireccionales que aceptan los cambios en las mujeres, pero no a la inversa. Es decir, "muy pocos son compañeros activos" (García Colmenares, 2002: 64). Conseguir que este cambio de actitudes se traduzca en un 
comportamiento acorde con la disposición verbal es una tarea común, en la que tienen especial importancia los cambios que las propias mujeres puedan llevar a cabo. Estos cambios implican movimientos dirigidos a la modificación de las identidades y la formación de la identidad es un proceso complejo, en el que se dan cita tanto elementos colectivos como individuales.

La identidad de género no se produce sólo enmarcada en la relación padres e hijos; padres y madres están actuando como mediadores de la sociedad en su conjunto, y como las sociedades humanas se caracterizan por el cambio, también podemos decir que así lo harán las identidades que les corresponden.

En la actualidad, y con el creciente proceso de incorporación de las mujeres al trabajo productivo, éstas se enfrentan a dos modelos diferentes de ser mujer: "por un lado, el que lleva asociados los valores tradicionalmente femeninos, como el cuidado de los otros o las actitudes de sumisión; y por otro, el nuevo modelo de mujer trabajadora, que se ha incorporado al ámbito público y que ha desarrollado actitudes de competitividad y autonomía para desenvolverse en ese medio" (García Colmenares, Carranza y Puleo, 2002: 24). Esas actitudes — que también se traducen en aptitudes - de competitividad y autonomía, cuando se traspasan a la esfera de lo doméstico, se encuentran con la resistencia que opone el todavía vigente sistema patriarcal y provocan disfunciones, conflictos e interpretaciones de la realidad contrapuestas, lo que da lugar al malestar y a la expresión del mismo en comportamientos de rechazo hacia ese nuevo modelo femenino, que no agrada a los demás y que está en proceso de agradarse a sí mismo, en la medida en que está en proceso de construcción.

Esos modelos son ojos para que las mujeres miren la realidad que les circunda, pero sobre todo para mirarse a sí mismas, para reconocerse en la nueva realidad, que está transformándose, tanto más cuanto que las miradas femeninas van ganando terreno, van cobrando la capacidad de definir y no 
sólo de ser definidas, en un movimiento creciente de empoderamiento que las convierte en sujetos del conocimiento y no en meros objetos.

Hemos creído ver en la obra de Icíar Bollaín Te doy mis ojos una forma interesante de abordar estas cuestiones y sobre ellas reflexionaremos más adelante.

\section{La violencia doméstica: definición y explicaciones teóricas}

Cuando comenzamos a revisar la literatura relacionada con la violencia que sufren las mujeres, nos encontramos con gran diversidad de conceptos: se habla de violencia de género, de violencia contra las mujeres, violencia familiar, violencia doméstica, etc. En este trabajo utilizamos la denominación violencia doméstica, que ha sido rechazada por algunas autoras (ver, por ejemplo, Marugán y Vega, 2001: 111), porque creen que oculta tanto a los sujetos como a las raíces de las agresiones. La alusión al espacio doméstico como el espacio de "lo privado" connota, según ellas, una solución intrafamiliar y nos alejaría de soluciones más estructurales. Nos hacemos eco de esta llamada de atención, y aclaramos que, en este trabajo concreto, elegimos la denominación violencia doméstica, para referirnos a un tipo concreto de violencia de género o contra las mujeres, que se manifiesta en una clase de comportamientos abusivos (físicos, sexuales o emocionales) que se dan en el contexto de una relación afectiva cercana, ya sea entre parejas casadas, que cohabitan o ex parejas. No se limita sólo a los miembros de la pareja (sea ésta heterosexual u homosexual), sino que a veces afecta también a los descendientes o a otros miembros de la familia. La existencia de ese vínculo afectivo, amoroso, es fundamental para entender el análisis de la obra que hemos elegido, aunque no por ello menospreciamos los aspectos socioculturales y estructurales sobre los que se sustenta tal sentimiento. Otras formas de violencia contra las mujeres, como la que tiene lugar en la comunidad en 
general, en el trabajo, en las instituciones educativas o en otros escenarios sociales, carece de esa carga afectiva y por ello entendemos que su comprensión, aunque parte del mismo marco estructural, que es la organización social patriarcal, debe hacerse teniendo en cuenta otros factores institucionales, que no estructurales. Con ello queremos hacer hincapié en que no estamos cayendo en el error generalizado, y no carente de intención, de confundir a la audiencia, haciendo pensar que víctimas y agresores están en el mismo nivel. Es un tipo de violencia contra las mujeres, ejercida por los varones, basándose en una posición de superioridad que les otorga la una organización social concreta: la patriarcal.

Centrándonos ahora en las explicaciones teóricas que se han elaborado para explicar la violencia doméstica, diremos que hay una serie de teorías de raíz psicoanalítica, psicosocial o conductual, que atribuyen la culpa de los malos tratos a factores individuales, sean estos psicológicos o fisiológicos, que afectan tanto a la víctima como al agresor, lo que tiene el efecto de despolitizar el problema al situarlo en el terreno individual y enviarlo al terreno profesional, terapéutico. Estos enfoques potencian la conveniencia de ser tratado institucionalmente, pero de manera privada. Es decir, se elude el componente estructural que la cuestión requiere para poder ser entendida en su totalidad.

Las explicaciones individuales que se centran en el comportamiento de los hombres los tratan, bien como enfermos o psicológicamente trastornados (Maynard, 1993; Dobash y Dobash, 1992; Bograd, 1998; Ptacek, 1998). Otras aluden a un supuesto ciclo de transmisión generacional de la violencia, según el cual el agresor ha aprendido una conducta que posteriormente reproduce. El alcohol o el consumo de drogas en general suele ser también una de las explicaciones más aceptadas, así como las que se refieren a la pérdida ocasional del control sobre sus actos, a estallidos de ira incontrolados o a una combinación de factores psicosociales que serían los que causan tal cantidad de estrés en los hombres que les llevaría a comportarse de esa manera. Cual- 
quiera de estas situaciones tiene que ver con el control, pero como señala muy acertadamente McConell, "no con perderlo, sino con utilizarlo para dominar la voluntad de otra persona: la mujer maltratada" (1991: 3).

Por lo que se refiere a las teorías de corte individualista, que se centran en las características de la víctima, es decir, de las mujeres, se han ofrecido explicaciones que van desde las que consideran que ellas lo merecen o lo provocan por su comportamiento (son gruñonas o provocadoras) a las que las presentan como masoquistas, adictas a la violencia, y las que atribuyen el hecho de no salir de esa situación a factores culturales o tienden a minimizar el alcance de los abusos, pues argumentan que, si fueran tan graves sería lógico pensar que la mujer no lo soportaría. Todas ellas tienen en común un efecto perverso que es culpabilizar a la víctima de lo que le está ocurriendo, eludiendo fijar la mirada en el contexto social y animando a las mujeres a creer en esos mensajes y a sentirse lo bastante culpables como para seguir soportando los malos tratos.

Como formuló Ryan (1971), a las víctimas se les echa la culpa por los fallos de sus superiores sociales, y esta tendencia se ve completada con la solución de centrarse solamente en la víctima, que es la que adoptan los que tienen el poder para articular respuestas ante el problema.

Los sociólogos insistimos en la idea de que para poder entender estas situaciones es necesario acudir al concepto de socialización diferencial, basándonos en la existencia de un modelo masculino tradicional que se apoya en dos conceptos: la restricción emocional y la obsesión por los logros y el éxito. En el marco de una sociedad patriarcal, la identidad masculina se construiría como negación de todo lo que es culturalmente definido como femenino. Por otra parte y desde una perspectiva ecológica, Strauss y Gelles (1986) se centran en los conceptos de poder y género dentro del ámbito familiar que convierten a la familia en una organización jerárquica en la que la violencia es un modo que utilizan los más fuertes para mantener el control de la relación. Este 
modelo ecológico, que es, desde nuestro punto de vista, el más adecuado, se articula en torno a la relación que se establece entre cuatro niveles sociales. El primero es el macrosistema, que comprende la organización social, con sus jerarquías establecidas e inamovibles y su distribución desigual de poderes, así como las creencias y los estilos de vida. De él parten las concepciones del deber ser, en este caso de lo que hombres y mujeres deben tener y hacer y de cómo deber ser la familia. Se refiere, pues, a los estereotipos de género dentro de la familia (y de otras instituciones sociales) y establece las prescripciones de rol. Igualmente, en este nivel se establecen las concepciones acerca del poder y el uso de la fuerza para hacer frente a los conflictos. El segundo nivel sería el llamado exosistema, y está integrado por las instituciones que actúan de mediadoras entre la cultura y el espacio individual: escuelas, iglesias, medios de comunicación, órganos judiciales, legislación, etc. Las creencias, los valores culturales que emanan del microsistema no son entidades abstractas, sino que se transmiten, fortalecen, recrean y modifican a través de estas instancias concretas en las que se produce la interacción cotidiana. Las figuras de autoridad que operan dentro de estas instituciones (maestros, sacerdotes, psicólogos, jueces, padres) son los transmisores de esos mandatos sociales y sirven de enlace entre los mandatos sociales y los sujetos individuales. El tercer nivel, sería el microsistema, y se refiere a las relaciones cara a cara. En este espacio se concretan los mandatos sociales sobre el deber ser en situaciones cotidianas. La familia es uno de los lugares privilegiados para esa concreción, en la medida en que, como grupo primario que es, se caracteriza por esa interacción cercana, continuada y con una elevada carga afectiva. En ella se despliegan y controlan los mandatos sociales que emanan de los dos niveles anteriores. En ella se aprende a ser hombre o mujer concreto y se hacen patentes las relaciones de poder y jerarquía establecidas en los niveles anteriores. Señalar, como lo han hecho algunos autores con anterioridad, que la familia es, después del Ejército y el Estado, una de las instituciones más violentas es una imagen que se resiste a hacerse pública y ésta es una de las 
razones por las que todavía resulta muy difícil calificar estos comportamientos como puramente delictivos. Gelles y Cornwell (1985) y Giddens (1993) nos recuerdan cómo es más probable que una persona sea atacada físicamente, golpeada, abofeteada o azotada en su propio hogar por otro miembro de la familia que en cualquier otro lugar o por cualquier otra persona en nuestra sociedad. Finalmente, estaría el nivel individual, que se refiere a las maneras en que cada individuo percibe y conceptualiza el mundo, las emociones, las ansiedades, los conflictos y las pautas de relación con los demás. Aunque es cierto que de este nivel emana la diversidad humana, las diferencias individuales, en definitiva, la libertad de cada ser humano para poder elegir entre una conducta u otra, e incluso para innovar, no lo es menos que este ámbito no puede entenderse sin hacer referencia a los tres niveles anteriores; es esta interrelación la que nos permite comprender el comportamiento individual concreto y es desde ella desde donde debemos partir, a la hora de explicar por qué un hombre en particular, se comporta de manera violenta contra una mujer, en este caso contra la mujer que ama. En definitiva, este modelo sociocultural toma en cuenta las características de la sociedad en su conjunto, y de las diversas instancias que emiten mandatos específicos para regular el comportamiento de cada persona. Entender por tanto por qué se produce la violencia contra las mujeres, sea en el ámbito doméstico o en otros contextos sociales, implica poner los comportamientos individuales en relación con los roles y estereotipos sexuales que emanan del macrosistema, se transmiten a través de las instituciones del exosistema y se concretan en las relaciones cara a cara del microsistema. Combinando esta aproximación ecológica con una perspectiva feminista, nos damos cuenta de que la violencia en el hogar se produce porque en él hay unas relaciones jerarquizadas que responden a una organización social patriarcal. Dichas relaciones no se generan en cada familia, sino que son el reflejo de estructuras sociales más amplias, por lo que el maltrato a las mujeres dentro de una relación familiar no puede ya más ser contemplado como algo individual, ni un asunto que compete sólo a la 
familia. Es, por el contrario, la afirmación de un orden social particular, que tolera la subordinación de las mujeres y el uso de la violencia en su contra. Desde esta óptica no sería una conducta desviada, ya que es promovido por un orden social basado en la desigualdad y que tiene interés en mantener y perpetuar esos esquemas de dominación. Como señala A. M. Pérez del Campo: "La sociedad no quiere hacer frente a una situación que percibe como de la vida privada, cuando no hay delitos íntimos ni privados: el delito, cuando es, es siempre público". Sin embargo, la realidad se aleja bastante de esta afirmación, y lo cierto es, que como sabemos, la violencia contra las mujeres es el crimen encubierto más extendido del mundo. Según el Informe Mundial sobre la Violencia y la Salud elaborado por la OMS y publicado en 2002, se documenta que casi la mitad de las mujeres que mueren por homicidio son asesinadas por sus maridos o parejas actuales o anteriores, un porcentaje que se eleva al 70\% en países donde no hay altos índices de delincuencia, problemas graves de seguridad, ni conflictos armados. En el mismo informe se señala que una de cada cuatro mujeres será víctima de violencia sexual por parte de su pareja en el curso de su vida. En una tercera parte o en más de la mitad de los casos se producen también abusos sexuales. En algunos países, hasta una tercera parte de las niñas han sufrido una iniciación sexual forzada.

En España los datos son también alarmantes. Desde 1999 hasta diciembre de 2004 el número de mujeres fallecidas como víctimas de la violencia de género asciende a 467. Sin embargo, esto es sólo la punta del iceberg, ya que sabemos que la cifra negra de este tipo de delitos es muy abultada. No tenemos datos fiables sobre cuántas mujeres están sufriendo tortura y violencia cotidiana en sus casas, aunque esto no tenga como resultado la muerte; no sabemos cuántas mueren como consecuencia de lesiones o enfermedades que tengan que ver con el maltrato continuado, ni el número de ellas que ante el sufrimiento, se suicidan. 
¿Qué pueden hacer las mujeres maltratadas ante tal estado de la cuestión? A este interrogante parece que en los últimos tiempos se ha dado como solución casi única el acudir a solicitar ayuda o asistencia institucional pues, como señala la Asociación pro Derechos Humanos (1999: 48) en un excelente trabajo sobre las actitudes y representaciones sociales sobre la violencia familiar, no hay referencia alguna sobre mujeres que salieron de su hogar y lograron superar la situación por sí solas o con ayuda de sus familiares y/o amigos:

Los relatos con final feliz están por completo ausentes en el discurso de las instituciones y el recorrido experiencial de las mujeres sujeto de este problema se construye en una dirección única: el sufrimiento en cualquiera de sus múltiples formas. Las imágenes de sacrificio y aislamiento configuran el destino ineludible de las mujeres que no denuncian públicamente la situación de violencia que padecen en su hogar. La imagen del miedo frente al riesgo de sufrir mayores males físicos se asocia al destino de las que así lo hacen. Y, frente a estas imágenes, se ofrecen las instituciones como única salida posible.

Pues bien, la obra de Icíar Bollaín es un cuento con final feliz, de los que pueden ayudar a las mujeres a imaginar que sí hay soluciones posibles, al margen de la exclusión y el sufrimiento seguros, que se ofrecen casi como ineludible destino a las víctimas de la violencia. Pero además es una manera de mirar a este problema social que regala aire fresco a nuestras anquilosadas propuestas prácticas. 


\section{La importancia de la mirada femenina}

A continuación vamos a exponer en síntesis el argumento del film elegido para esta discusión, para pasar posteriormente a un análisis más pormenorizado.

La obra comienza una noche de invierno, en la que una mujer, Pilar, sale huyendo de su casa. Lleva consigo a su hijo, Juan, y apenas cuatro cosas. Su marido, Antonio, no tarda en ir a buscarla. Según dice, para él Pilar es su sol y además "le ha dado sus ojos". A lo largo de la película, nos vamos dando cuenta de que la razón de la huida es la conducta violenta de Antonio e iremos viendo qué ocurre cuando ambos intentan poner fin a esta situación. Pilar y Antonio son los personajes centrales, rodeados por otros, que aunque parecen tener un carácter secundario, son esenciales para entender la propuesta de la autora.

Ana, la hermana de Pilar, una chica independiente, que tiene su propio trabajo, convive con un novio irlandés, en una relación que se nos presenta como bastante desapasionada, pero muy respetuosa (un modelo de convivencia muy contemporáneo). Ana representa a todas las personas que quieren ayudar, pero no saben cómo, porque en el fondo no entiende qué es lo que pasa. Con toda su buena intención no consigue ayudar a su hermana porque simplifica algo muy complejo (casi como la mayoría de la gente).

La madre de Pilar y Ana es un personaje que silencia el problema y que por tanto lo consiente, como se ha venido haciendo tantos años; representa la posición más tradicional y aunque la autora no la presenta como deseable, no quiere que pase desapercibida. Después de todo, ésta sigue siendo la respuesta más habitual en la mayoría de los casos.

Además está el psicólogo de Antonio, la única persona que parece capaz de entenderle, y de decirle lo que debe y lo que no debe hacer. Con este personaje Bollaín nos sugiere que debemos centrarnos en los varones para 
conseguir que el problema se solucione y no centrarnos como se ha hecho hasta ahora casi exclusivamente en las mujeres. Son los varones quienes producen el problema en lo público y en lo doméstico, luego hay que incluirlos, no sólo para combatir judicialmente sus comportamientos - aunque esto es fundamental para deslegitimar e ilegalizar la violencia—, sino también para convertirlos en los sujetos centrales de la prevención y también de investigación. Esto contribuye, en la práctica, a comprometer a los varones a romper el silencio cómplice y a luchar activamente contra la violencia.

Finalmente estarían las amigas de Pilar, sus compañeras de trabajo, que como veremos serán esenciales en la propuesta de solución que se nos ofrece.

La obra de Bollaín no serviría para explicar todos los casos de violencia doméstica, pero sí para algunos en los que el hombre define su situación como de pérdida de amor, del amor que además les confiere su propia identidad. Es la imagen que Garrido Genovés (2001: 144-145) define como el agresor dependiente y que Lorente Acosta (2001: 73) conecta con el contexto social cuando expone:

Los celos también tienen una importante parte de construcción sociocultural; no se es celoso del mismo modo y ante las mismas situaciones en diferentes sociedades, ni se reacciona e interpretan de la misma forma determinadas conductas posesivas que son revestidas de amor. "Si no es celoso es porque no te quiere", les dicen a muchas mujeres, con lo cual el mensaje es claro: si es celoso es porque te quiere, y cuanto más celoso más amor; y si te quiere es normal que ante determinadas situaciones intente defender ese amor. 
Los celos, en el fondo, son un mecanismo que persigue el control de la otra persona y, en parte, muestran el miedo, la inseguridad y la dependencia del que los ejerce. Es por eso que son una buena excusa para el hombre, una explicación suficiente para la mujer, una adecuada justificación para la sociedad y una atenuante o eximente lícita para la Justicia. Pérez Abellán (2002: 10) nos sitúa más en el centro de la diana explicativa:

En otras épocas eran asuntos pasionales, crímenes de amor, pero en realidad son crímenes de desamor. La hembra muere a manos de su propietario, el ser que se erige en su único poseedor.

Y esto viene ilustrado por más de 50 casos reales. Marie France Irigoyen, autora de El acoso moral, lo define como un perverso narcisista, un ser que a falta de haber podido construir su propia identidad, necesita destruir la de su víctima para sobrevivir. Campo Ladero (2003: 50) señala en su informe que "el nuestro es un país donde impera el amor romántico, de ahí que la confianza entre la pareja sea muy valorada". Asimismo se señala la fidelidad por un $98 \%$ de la población como uno de los aspectos más valorados para el buen funcionamiento de la pareja.

Desde nuestro punto de vista la clave para entender qué es lo que ocurre entre los protagonistas de la cinta (Pilar y Antonio) es ese amor romántico, entendido como una relación de entrega total entre ambos. La pareja cae en manos de un sentimiento irracional, de una atracción que parece inevitable y que les conduce a la ceguera. No olvidemos que Cupido se nos representa con los ojos vendados. Al final de la película Pilar dice: "Necesito mirarme, no sé quién soy".

Pilar no se ha mirado a sí misma porque se ha construido a través de la entrega a los demás. Ha sido una buena hija, lo que para ella significaba satisfacer las demandas de los otros, de su padre (también maltratador), de 
su madre que le ha enseñado que ella aguantaba esa situación por sus hijas, porque además "todo el mundo tiene algo" o se explica su propia situación con algo tan inconcreto como la alusión a que, en lo privado, nadie debe inmiscuirse ("tú qué sabes qué hay entre los dos" le dice a su hermana).

El modelo de la madre representa un estadio anterior en el que la sociedad consideraba lo privado como sagrado y el modelo femenino ligado no sólo a la entrega sino también al sufrimiento. No es casual el recorrido que durante el film se hace a las imágenes de la catedral de Toledo, todas ellas ligadas a esa concepción cristiana católica del mundo terrenal como un valle de lágrimas. Es muy significativo el momento en el que las hermanas contemplan la imagen de la dolorosa y Ana le dice a Pilar: "Acaba de darse cuenta de que ha salido a la calle con zapatillas" (cuando Pilar abandona su casa por primera vez después de una paliza, lo único que alcanza a decirle a su hermana es que se ha olvidado de quitarse las zapatillas). Todas las mujeres sufren, todas alguna vez quieren huir, aunque sea en zapatillas de la situación de dominación, sometimiento y sufrimiento que la entrega continuada a los demás produce. Y la Virgen representa este modelo como ninguna.

Quizá ésta es la primera vez que Pilar se empieza a mirar a ella misma, a reconocer que está sufriendo por algo que le falta a ella y no a los demás. Ella ha pasado de ser en función de su familia a ser en función de Antonio. Ha sido una individualidad anulada por la entrega a los otros. A lo largo de la película la vemos continuamente acompañando a su hijo, ayudándole a hacer los deberes, jugando con él, leyéndole cuentos, enseñándole a mirar, ofreciéndose a hacer la cena a su marido. Sus deseos, sus impulsos, sus preferencias (el I meadiano) están anulados por un "me" sobredimensionado.

El círculo vicioso en el que se instala la relación entre Antonio y Pilar es el de la dependencia. Él le repite constantemente que sin ella no es nadie, que con ella lo puede todo. El poder para Antonio reside en la posesión de la parte más íntima de Pilar. Quiere saber constantemente no sólo dónde está 
físicamente sino lo que piensa, lo que desea, hasta lo que sueña (como se lo hace notar al psicólogo en una de sus crisis). Es esa necesidad de poseer al otro en su totalidad, sin dejarle espacio siquiera para mirarse (clave de la película), lo que le conduce a esos estallidos de ira, a la pérdida del propio control (en realidad a desplegar mecanismos de control sobre Pilar).

Vemos cómo aparece aquí una mezcla de las explicaciones que exponíamos al principio acerca de por qué los hombres agreden (las que combinan la socialización diferencial con las psicológicas y la ecológica). La ira es una expresión del miedo, miedo a perder al otro, que es quien otorga el poder. Cuando Pilar lee en el diario de Antonio los síntomas de estos estallidos, ella reconoce que son los mismos que produce el miedo y que ella conoce perfectamente.

Ese miedo es consecuencia de una baja autoestima. Antonio mantiene con su hermano una relación que le hace sentirse muy poco valorado. Esto puede verse cuando él pregunta al psicólogo por qué habría de quedarse Pilar junto a él. Siente que no tiene nada que ofrecerle, nada de qué hablar, nada material, se siente muy poca cosa porque no cree que tenga nada que dar (en su petición de matrimonio le ha entregado sus manos a Pilar). El psicólogo le recuerda que se quedará con él si la quiere, si no la maltrata, si la respeta; en definitiva, si le permite mirarse a sí misma como un individuo particular, no como parte de sí mismo.

Pero el problema de Antonio es que no puede aceptar que ella tenga una vida propia, unos deseos propios, unos sentimientos particulares, que goce de nada que no tenga que ver con él. Cuando la ve comentar los cuadros, se encuentra ante una persona con mirada propia y eso es para él insoportable. Está disfrutando explicando a otros sus miradas y proyectándolas en los cuadros, y para él esto es una infidelidad en sí misma. Pilar se ha convertido en un individuo independiente, a quien los demás también pueden ver y a quien ella ofrece su propia visión (sus ojos) y eso constituye para él una traición 
puesto que ella se los entregó. Él dice: "Es otra persona, lo noto en todo, en su mirada, en su aspecto, está más guapa".

Es curioso notar cómo el vestuario de Pilar, su peinado, se mantiene sobriamente constante a lo largo de la cinta. El pelo recogido en un moño, la ausencia de maquillaje, de ornamentación, los jerseys lisos, simples, sin escotes, sin insinuaciones. Y sin embargo, él la ve más guapa cuando está delante de los demás, pues a medida que ella se va apropiando de su mirada aparece como una persona más deseable. Él sin embargo no es capaz de tomar esa distancia, puesto que Antonio depende desesperadamente de los ojos de Pilar.

No admite que nadie vea lo que su mujer tiene de particular, lo que le es propio como individuo independiente, lo que puede atraer a los demás y por eso la castiga, en una de las escenas más duras de la película, a aparecer desnuda ante los vecinos. No le importa que ellos vean su cuerpo si es él quien lo enseña. La verdadera afrenta para él es que sea ella quien, como ser autónomo, se presente ante los demás. Lo que Antonio no puede soportar es la separación de esa parte de su yo. El cuerpo de su mujer es suyo y con él toda su independencia como persona. La relación se ha basado en la entrega y no en la capacidad de relacionarse como individuos separados. Él no tiene sueños, no desea nada, sólo se construye a través de la posesión de otro, porque por sí mismo no es nadie y hace todo lo posible para retenerla a su lado (amenaza con quitarse la vida y al final parece que lo intenta). Incluso la asistencia a la terapia parece más una estrategia para que ella vuelva ("estoy yendo al psicólogo, ¿vuelves a casa?”) que un verdadero intento de cambiar como persona.

Pilar es el verdadero pilar de Antonio. Con toda su fragilidad, se presenta en la película como la base de la relación. Ella es una mujer asustada pero firme; él sin embargo no sabe quién es, se busca constantemente a través de ella. Le envía regalos para que vuelva, lo que parece ser un símbolo de 
arrepentimiento, pero nuevamente no son más que estrategias para conseguir que ella vuelva, pues nadie la quiere más que él, nadie la conoce mejor que él. Éste es un comportamiento bien documentado en los casos reales que conocemos (fases de estallido, seguidas de arrepentimiento y entrega absoluta y vuelta a empezar). Es una conducta utilitarista, pues como dice uno de los asistentes a la terapia, "con eso parecía que conseguía que me respetara", es decir, eso les convierte en alguien, en concreto, en un hombre que, como tal, tiene derecho a exigir ese respeto, a ejercer en definitiva el poder que le confiere haber nacido varón, en una sociedad que los coloca en situación de superioridad.

También es interesante señalar que, en contra de las explicaciones que atribuyen a las mujeres maltratadas un carácter masoquista, lo que se ve claramente es cómo el miedo se instala en la mujer maltratada (Pilar tiembla sólo ante la amenaza) y cómo ella mantiene la relación mientras le permite tener cierto espacio como persona, cierto deseo de amar al otro. Esto se rompe totalmente cuando él la convierte prácticamente en un muñeco en la escena en que la desnuda frente a los demás, cometiendo un atropello que ella ya no es capaz de soportar, pues es la anulación total como sujeto.

Cuando ella pone la denuncia dice: "Mi marido lo ha roto todo; lo ha roto todo por dentro", y es en ese momento cuando ella está segura de que ya no le va a querer más. No hay por tanto disfrute alguno en el maltrato. Acaso lo que persista es la necesidad de amar al otro, la pasión por encontrarse con el otro, pasión que no puede aflorar una vez que la ha convertido en un objeto. El objeto no puede amar, sólo ser amado o deseado por otro y así es como se queda Antonio, cuando ella se va de casa, como mirando a un objeto.

Muchas mujeres maltratadas, rotas por dentro como Pilar, no podrán conseguir sus deseos de alejarse. La directora, creemos que con intención pedagógica, nos enseña sin embargo una solución posible y alternativa a la institucionalización: el apoyo social. 
Pilar puede irse porque tiene el apoyo incondicional de su hermana, pero también, y muy importante, de sus amigas, de sus compañeras de trabajo, que no en vano se nos presentan como un grupo de mujeres que, conocedoras del juego perverso de las relaciones hombre-mujer (es muy esclarecedora la escena en la que cuando una de ellas viene a ser recogida por su novio tras una discusión, reproducen irónicamente el supuesto diálogo entre ambos) descreen por completo del amor romántico.

Ellas representan la otra mirada, la que le permitirá a Pilar recuperar por fin sus ojos. Y esto es lo que nos parece verdaderamente novedoso en la propuesta de Bollaín: enseñar a las mujeres a mirar el mundo desde otra perspectiva, con otros modelos que nos permitan vernos a nosotras mismas liberadas del mandato de la dependencia y la entrega incondicional hacia los demás, con una mirada que nos permita nombrar el mundo desde la igualdad, que sólo es posible si nos convertimos en sujetos de conocimiento, en dueñas de la capacidad de nombrar.

\section{Consideraciones finales}

La película que hemos analizado no constituye únicamente una explicación de por qué se produce a veces la violencia doméstica. Nos sitúa además ante dos modelos de género incompatibles, dos modelos imposibilitados para el amor, porque si el amor implica entrega, lo que se deduce es que hay que tener algo que dar y uno de esos modelos implica la anulación de la capacidad de hacerlo, porque ni siquiera se le da la oportunidad a una de las partes de ser sujeto. El amor romántico se basa en la atracción mutua entre dos sujetos. Tal como expone Boswell (1995), el amor romántico es una obsesión en la moderna cultura industrial y se sustenta en la creencia de que el objetivo de un hombre es amar a una mujer y el de una mujer amar a un hombre. Pero el sistema patriarcal tiene como efecto perverso la anulación de uno de esos componentes de la díada amorosa. 
En principio parecería que esas partes son complementarias: una aportaría lo que le falta a la otra; pero esa supuesta complementariedad ha conducido en la práctica a la anulación de una de ellas. Hombre y mujer son dos componentes de un todo, pero uno se define como activo y otro como pasivo, uno posee razón y el otro carece de ella, uno ejerce el control y el otro representa el descontrol emocional, las demandas irracionales e ilógicas. Es decir, son identidades no sólo antitéticas sino que, además, la afirmación de una conlleva la destrucción de la otra.

Para que el hombre pueda cumplir con las prescripciones de su rol, con su imaginario colectivo, debe ser dominante, exitoso, no empático, ni blando, ni emocional, ni dependiente; en definitiva, su identidad se construye a través de la negación de su complementaria. Como expone Laura Asturias (2002: 11-12):

los hombres aprenden a ejercer el poder sobre las mujeres, y este ejercicio incluye no escuchar la voz de las mujeres, subordinar los deseos y la voluntad de ellas a los suyos, y concentrarse en el cuerpo femenino como un objeto y una imagen y no como la expresión integral de una persona completa, consciente, con derechos y sentimientos. Y han aprendido también que su poder patriarcal es natural y no puede ser cambiado, lo cual forma parte de la ideología del sexismo, que justifica y legitima la opresión de las mujeres. Sin embargo, el poder patriarcal sí puede ser transformado en un modelo de convivencia más equitativo.

Diríamos que el modelo masculino propuesto en la sociedad patriarcal lleva el germen de su propia autodestrucción, en la medida en que llega un momento en el que la miseria de la condición femenina es tan grande que ellas empezarán a tomar conciencia de la opresión que supone plegarse al ideal de feminidad impuesto, y esto les hará tomar las riendas para conse- 
guir su libertad. Libertad que no es sinónimo de egoísmo, sino una cualidad necesaria para poder acercarse a los otros. No se puede conseguir la libertad a costa de la opresión de los demás. El que esclaviza acaba siendo el reo de sus propios anhelos, como Armiñán contó magistralmente en Stico y como lo demuestra nuestra propia Historia. Los regímenes esclavistas acaban siempre sucumbiendo, puesto que convierten a unas personas en propiedad de otras, y esto sí que va en contra de la naturaleza humana, que es esencialmente social y esencialmente cooperativa, como Marx, Mead y Cooley, entre otros, nos han sabido hacer ver. Y aunque esta característica parece haberse aplicado sólo a los hombres, inexcusablemente ha de ser puesta en práctica para con las mujeres, puesto que la naturaleza humana no es patrimonio exclusivo de los varones.

Lo que vemos en esta película, por tanto, son dos roles de género que ya no pertenecen al mismo universo simbólico. Antonio representa el modelo patriarcal tradicional, sexista y todavía dominante, y Pilar es una representante de los deseos de las mujeres actuales que, rebelándose contra la ceguera y la negación, inician un nuevo camino, o lo que es lo mismo, están construyendo un nuevo modelo, y en este movimiento se construyen a ellas mismas y también a los varones que, necesariamente están teniendo que cambiar, puesto que les falta la base sobre la que se sustentaba su identidad.

Ésta es una tarea urgente ya que los modelos son esenciales porque nos permiten orientarnos, prever en buena medida la interacción con los otros: posibilitan por tanto la vida social. El sistema tradicional de dominación masculina dividió a las personas en dos tipos y a uno de ellos le despojó de su esencialidad: la palabra. Víctima de su fisiología, la mujer se presentó como un ser dependiente, incontrolado e incontrolable, alejado de la razón y la inteligencia; un apéndice al servicio del poder sinónimo de masculinidad. Pero las personas (hombre o mujeres) poseen la capacidad simbólica, a pesar de que las restricciones históricosociales y culturales hayan pretendido 
arrebatárnosla. Aunque durante siglos se nos haya convencido de que éste es el orden natural, lo cierto es que, en determinadas situaciones socioestructurales - como la que vivimos fundamentalmente en el mundo occidental, esa evidencia se abre paso indefectiblemente. Como dice Rivera Garretas (1994:12):

Para nombrar el mundo hay que ponerse en juego en primera persona. Ponerse en juego en primera persona quiere decir arriesgarse a juntar, también cuando se habla o se escribe, la razón y la vida (...) Juntar lo que los filósofos occidentales llaman la cultura y la naturaleza es una necesidad que históricamente hemos sentido y sentimos especialmente las mujeres en las sociedades patriarcales. Porque la separación entre palabra y cuerpo (....) hace que las mujeres vivamos en un desorden simbólico casi permanente, desorden que nos empuja con especial urgencia a la búsqueda personal de sentido, del sentido de nuestro ser y de nuestro estar en el mundo. Por eso se dice a menudo, no sin cierto rencor, desde el conocimiento con poder, que ellas cuando escriben se dedican incurablemente a contar su vida, sugiriendo que este contar su vida no puede alcanzar las cimas de la objetividad del arte universal. Y, sin embargo, esto es invertir el orden de las cosas, porque el arte de nombrar el mundo coincide precisamente con el arte de decir originalmente ella o él su vida.

Pilar no es una feminista, pero sí es una consecuencia de las demandas de este movimiento que, en una primera ola, reivindicó la igualdad de derechos y oportunidades y una mayor representación política, esfera de la que habíamos sido tradicionalmente excluidas, y que en una segunda oleada, enarbolando el lema de que "lo personal es político", ha querido concienciar a la sociedad de que el poder estaba también presente en el ámbito de lo pri- 
vado, arrebatándonos nuestro derecho de ser personas.

Muchas mujeres (como Bollaín y sus personajes femeninos) tenemos puesta la mirada en nuestra estación de destino; un lugar que nos permita ejercer aquello que Aristóteles señalaba como la esencialidad del ser humano: la palabra. Palabra que nos permitirá superar a la naturaleza y que implica que podamos situarnos moralmente frente a la sociedad y la cultura humanas. Esto es, que podamos inclinarnos hacia el bien o hacia el mal. En definitiva, que podamos elegir en libertad.

Perdamos pues el miedo a nombrarnos y tomemos las riendas de nuestros destinos creando modelos que nos liberen del mandato patriarcal que nos obliga a darlo todo sin pedir nada a cambio.

\section{BIBLIOGRAFÍA}

Asociación Pro Derechos Humanos (1999). La violencia familiar. Actitudes y representaciones sociales. Madrid: Fundamentos.

Bograd, M. (1988). "Feminist perspectives on wife abuse: an introduction". En Yllö, K. y Bograd, M., Feminist Perspectives on Wife Abuse. Newbury Park, CA: Sage.

Bonino, L. (1998). "Los varones frente al cambio de las mujeres". En Revista Lectora. Monográfico hombres y feminismo. UAB, pp. 7-22.

Boswell, J. (1995). The Marriage of Likeness: Same-sex Unions in Pre-modern Europe. Londres: Fontana.

Campo Ladero, M. J. (2003). Relaciones Interpersonales: Valores y Actitudes de los españoles en el nuevo milenio. Madrid: CIS.

Dobash, R.E. y Dobash, R. P. (1992). Women, Violence and Social Change. Londres y Nueva York: Routledge.

García Colmenares, C., Puleo, A. y Carranza, M. E. (2002). El trabajo y la salud de las mujeres. Reflexiones para una sociedad en cambio. Palen- 
cia: Ayuntamiento de Palencia y eds. Cálamo.

Garrido Genovés, V. (2001). Amores que matan. Alzira: Ed. Argal.

Gelles, R. J. y Cornwell, C. P. (1985). Intimate violence in families. Londres: Sage.

Giddens, A. (1993). Sociology (2a ed.). Cambridge: Polity Press.

Gracia Fuster, E. (2002). Las víctimas invisibles de la violencia familiar. Barcelona: Paidós.

Lorente Acosta, M. (2001). Mi marido me pega lo normal. Barcelona: Crítica. Maynard, M. (1993). "Violence towards women". En Richardson, D. y Robinson, V. (comps.), Introducing women,s Studies. Basingtoke: McMillan.

McConell, J.E. (1991). "Beyond Metaphore: battered women, involuntary servitude and the thirteenh amendment", ponencia presentada en la Conferencia interncional conjunta de la Law and Society Association $y$ el Research Committee on the Sociology of Law and the International Sociological Association, Amsterdam, junio de 1991.

Pérez Abellán, F. (2002). Mi marido, mi asesino. Barcelona: Martínez Roca.

Ptacek, J. (1988). “Why do men batter their wifes?”. En Yllö, K. y Bograd, M., Feminist Perspectives on Wife Abuse. Newbury Park, CA: Sage.

Ryan, W. (1971). Blaming the victim. Londres: Orbach and Chambers.

Strauss, M. A. y Gelles, R. J. (1980). Behind closed doors: violence in american family. Nueva York: Anchor. 